\title{
06 ANALYSIS OF THE CASES OF TRAUMA AND SUICIDE ATTEMPTS SERVICED BY UNIVERSITY GENERAL HOSPITAL 'TSARITSA YOANNA-ISUL', SOFIA OVER 1 YEAR PERIOD
}

doi:10.1136/injuryprev-2012-040590n.6

F Koycheva, B Korukov, R Hristova, E Yankov, D Karadimov, I Tzenev, R Popov. University General Hospital 'Tsaritsa Yoanna_ISUL', Sofia, Bulgaria

Aim To estimate the rate of hospital admissions for trauma and burns due to external causes (ICD-10) for a 1 year period in comparison with the overall number of admissions in a university hospital providing emergency services for a city with a population of 1.5 million. A secondary analysis involved identifying the types of external causes and assessing their preventability and cost.

Methods Analysis of case notes from five wards (Ophtalmology; Orthopedics and Trauma; Ear, Nose and Throat; Intensive Care; Neurosurgery) for the period of 1 January 2011-1 January 2012. The trauma cases and burns due to external causes as well as suicide attempts were summarised. The ratio between trauma due to extraneous causes and overall number admissions was calculated, the percentage of cases leading to long-term disability, their financial cost and the estimated cost of their prevention.

Results We found that preventable traumas due to external causes comprise a significant part of all admissions, with ophtalmology, hand trauma and suicide attempts in untreated psychiatric disorders contributing considerably. Our secondary analysis revealed a high percentage of long-term disability as a direct result of these preventable traumas. These data highlight the need to increase prevention efforts, as well as the need to register hospitalised patients under section 'External causes' of ICD-10 when appropriate. 